\title{
Eficácia da implantação das boas práticas de manipulação de alimentos em uma instituição de longa permanência para idosos
}

\author{
Fátima Lidiane Persch ${ }^{1}$,Carla Cristina Bauermann Brasil ${ }^{2}$, Luana Fioravanti Roland ${ }^{3}$, \\ Kellyani Souto Peixoto ${ }^{4}$, Andrieli Teixeira Corso ${ }^{5}$, Daiane Policena dos Santos ${ }^{5}$, \\ Emanueli Bergamaschi ${ }^{6}$, Fernanda Copatti ${ }^{6}$, Larissa Santos Pereira ${ }^{6}$ \\ e Tauani Lardini Tonietto 6
}

\begin{abstract}
Instituições de Longa Permanência para Idosos devem ofertar alimentos que atendam às exigências das Boas Práticas de Manipulação de Alimentos para que não haja nenhum risco à saúde desta população. O objetivo deste trabalho foi implantar as Boas Práticas em uma Unidade de Alimentação e Nutrição de uma Instituição de Longa Permanência para Idosos. Inicialmente, foi aplicada a Lista de Verificação em Boas Práticas de Manipulação de Alimentos da Portaria no 78 de 30 de janeiro de 2009, e logo após foram realizados procedimentos para a sua implantação; por conseguinte, a lista foi reaplicada in loco. Os dados coletados foram tabulados com auxílio do programa Microsoft Office Excel ${ }^{\circledR} 2013$ e a figura formulada por meio do programa GraphPad Prism versão 5.0. Após a aplicação inicial da lista a unidade avaliada apresentou 41,27\% de adequação. $\mathrm{Na}$ reaplicação, após implantação das ferramentas de controle de Boas Práticas, o percentual de adequação encontrado foi de 56\%. Este acréscimo de $14,73 \%$ entre as duas aplicações da lista de verificação fez com que a classificação da unidade elevasse para a categoria Regular. Ressalta-se a importância da implantação das Boas Práticas em serviços de alimentação, a fim de garantir a segurança alimentar aos idosos institucionalizados.
\end{abstract}

Palavras-chave: Manipulação de alimentos, boas práticas de manipulação, doenças transmitidas por alimentos.

${ }^{1}$ Nutricionista, egressa do curso de Nutrição da Universidade Federal de Santa Maria (UFSM) - Rio Grande do Sul, Brasil. E-mail: fatima.persch@hotmail.com

${ }^{2}$ Docente do Curso de Nutrição da Universidade Federal de Santa Maria (UFSM) - Rio Grande do Sul, Brasil. Endereço para correspondência: Rua Antônio Sangói Netto no 85 - Santa Maria, Rio Grande do Sul, CEP: 97035-090. Telefone: (55) 99973-3165. E-mail: carlacristina@brturbo.com.br

3Nutricionista, Mestra em Gerontologia pela Universidade Federal de Santa Maria

${ }^{4}$ Nutricionista, Especialista em Gerontologia pela Universidade Regional do Noroeste do Estado do Rio Grande do Sul.

${ }_{5}^{5}$ Acadêmica do Curso de Nutrição da Universidade Federal de Santa Maria (UFSM) - Rio Grande do Sul, Brasil.

${ }^{6}$ Nutricionista, egressa do Curso de Nutrição da Universidade Federal de Santa Maria (UFSM) - Rio Grande do Sul, Brasil. 


\section{Effectiveness of implementation of good practices of food handling in a long-stay institution for elderly}

In a Long Stay Institutions for the Elderly it is important to offer foods that meet the requirements of Good Food Handling Practices so that there isn't risk to the health of this population. The objective of this work was to implement the Good Practices in a Food and Nutrition Unit of a Long Stay Institution for the Elderly. Initially, the Good Manipulation Checklist of Food Handling of Ordinance n. 78 of January 30, 2009 was applied, and soon after were realized dealings for its implementation; therefore, the list has been reapplied. The data collected were tabulated using the Microsoft Office Excel ${ }^{\circledR} 2013$ program and the figure formulated using GraphPad Prism version 5.0. After the initial application of the list, the evaluated unit presented a $41.27 \%$ adequacy. In the reapplication, after the implementation of the Good Practices control tools, the percentage of adequacy found was $56 \%$. This increase of $14.73 \%$ between the two applications made the classification of the unit raise to category regular. Emphasis should be placed on the importance of Good Practices in food services and their implementation, in order to provide ensure food security for institutionalized elderly.

Keywords: Food handling, good manipulation practices, food borne diseases.

\section{INTRODUÇÃO E OBJETIVOS}

A segurança alimentar é uma exigência básica em todos os locais onde são fornecidas alimentação, sendo uma das principais preocupações no âmbito da saúde pública, principalmente por poder afetar a saúde dos grupos mais vulneráveis, como crianças, pessoas com necessidades especiais e idosos ${ }^{[1]}$.

Uma Instituição de Longa Permanência para Idosos (ILPI) é aquela fadada a propiciar atenção integral com condições de independência e dignidade, no qual o público alvo são as pessoas com mais de 60 (sessenta) anos, com ou sem estrutura familiar. Para atender idosos que necessitam de assistência, a instituição deve ter uma equipe multiprofissional, contando com uma nutricionista com carga horária de oito horas semanais a fim de garantir uma alimentação que respeite os aspectos culturais locais, oferecendo, no mínimo, seis refeições diárias ${ }^{[2]}$.

A fase da vida chamada velhice, causa modificações fisiológicas e psicológicas que podem refletir na saúde e no estado nutricional dos idosos, principalmente daqueles institucionalizados, o que pode causar alguns desequilíbrios alimentares. Devido a esse motivo é de extrema importância a oferta de alimentos não só balanceados nutricionalmente, mas também que atenda às exigências das boas práticas de manipulação de alimentos ${ }^{[3]}$.

No intuito de melhorar as condições higiênico-sanitárias que envolvem a preparação de alimentos em serviços de alimentação, a Agência Nacional de Vigilância Sanitária ${ }^{[4]}$ dispõe da Resolução da Diretoria Colegiada - RDC no 216, de 15 de setembro de 2004, que regulamenta as Boas Práticas de Manipulação de alimentos para serviços de alimentação[5]. Complementar a esta, o estado do Rio Grande do Sul possui a Portaria no 78 de 30 de janeiro de 2009, a qual aprova a Lista de Verificação em Boas Práticas (LVBP) para Serviços de Alimentação e recomenda cursos de capacitação em boas práticas de manipulação de alimentos ${ }^{\left[{ }^{[}\right]}$.

Recentemente foi traçado um perfil epidemiológico com os principais locais de ocorrência de doenças transmitidas por alimentos e água (DTAs) abrangendo todo o Brasil, tais como residências, restaurantes, escolas, hospitais e eventos. Este perfil constatou que $0,8 \%$ dos surtos, ocorreram em ILPIs, no período de 2009 a $2018[7]$.

Para evitar possíveis episódios de doenças causadas por alimentos contaminados em ILPIs devem ser adotados o cuidado em todo o processo produtivo com seus devidos controles, como o 
monitoramento do tempo e da temperatura, inclusive na distribuição dos alimentos, assim como as boas práticas de manipulação pelos manipuladores. Os procedimentos de escolha e compra dos produtos que serão utilizados para a preparação do alimento até a oferta ao consumidor são importantes, porém não tanto quanto o controle do binômio tempo e temperatura ${ }^{[4]}$.

Para realizar o diagnóstico de uma unidade de alimentação e nutrição é essencial a aplicação de ferramentas de gestão da qualidade ${ }^{[8]}$. Uma avaliação inicial permite identificar as não conformidades de todo o processo produtivo de alimentos desde a recepção da matéria-prima até o consumidor final e, a partir dos resultados encontrados, propor ações corretivas e preventivas para adequação das condições de preparo das refeições ${ }^{[9]}$.

Apesar da existência de estudos que aplicaram a lista de verificação em boas práticas em ILPIs, não há evidências científicas que relatam o processo de implantação desta ferramenta da qualidade no Brasil. Sendo assim, diante do exposto o objetivo deste trabalho foi implantar as Boas Práticas em uma Unidade de Alimentação e Nutrição de uma ILPI de uma cidade do interior do Rio Grande do Sul.

\section{MATERIAL E MÉTODOS}

Trata-se de um estudo de intervenção de caráter descritivo, realizado em uma unidade de alimentação e nutrição de uma ILPI de uma cidade do interior do Rio Grande do Sul que aceitou participar do projeto. Esta instituição comporta, atualmente, 58 idosos e possui uma equipe multiprofissional de saúde, incluindo a atuação de uma nutricionista.

O diagnóstico das Boas Práticas de Manipulação de Alimentos da unidade de alimentação e nutrição foi realizado com o auxílio de uma lista de verificação em Boas Práticas da Portaria no 78/2009[0].

A lista de verificação em boas práticas foi aplicada duas vezes na ILPI, durante o horário do processo produtivo de alimentos (manhã e tarde), durante cinco dias uteis. Destaca-se, que a segunda aplicação da lista de verificação foi realizada após as capacitações e implantação das Boas Práticas.

A lista de verificação em boas práticas foi aplicada por uma acadêmica do curso de nutrição da Universidade Federal de Santa Maria, previamente capacitada por docente da área, e contemplou 152 itens. Estes itens foram subdivididos em 12 categorias, sendo estas: Edificação, Instalações, Equipamentos, Móveis e Utensilios (categoria 1, $\mathrm{n}=34$ ); Higienização de Instalações, Equipamentos, Móveis e Utensílios (categoria 2, $\mathrm{n}=17$ ); Controle Integrado de pragas (categoria 3, $\mathrm{n}=7$ ); Abastecimento de Água (categoria 4, n=9); Manejo de Resíduos (categoria 5, n=3); Manipuladores (categoria 6, $\mathrm{n}=15$ ); Matérias-primas, Ingredientes e Embalagens (categoria 7, $\mathrm{n}=12$ ); Preparação do Alimento (categoria 8, $\mathrm{n}=26$ ); Armazenamento e transporte do Alimento preparado (categoria 9, $\mathrm{n}=6$ ); Exposição ao Consumo do Alimento preparado (categoria 10, $\mathrm{n}=9$ ); Documentação e Registro (categoria 11, $\mathrm{n}=7$ ) e Responsabilidade (categoria 12, $\mathrm{n}=7)^{[6]}$.

As alternativas presentes na LVBP que puderam ser preenchidas foram as seguintes: Sim; Não; Não se Aplica (NA); inclusão da opção Não Observado (NO). Na LVBP foram atribuídos valores às diferentes respostas (Sim e Não). Para as respostas $\operatorname{Sim}(\mathrm{S})$, se atribuiu o valor de 1 (um) ponto e as respostas Não (C) receberam nota 0 (zero).

O número de respostas Não Aplicáveis (NA) e Não Observados (NO) obtidos, foram subtraídos do total de itens, não sendo, portanto, computados na soma final. Além disso, a lista de verificação possuía um espaço destinado a observações realizadas pela avaliadora.

A unidade de alimentação e nutrição da ILPI foi classificada de acordo com Saccol; Hecktheuer e Stangarlin[10] que dividem os estabelecimentos em cinco grupos: Grupo 1 Muito bom (91 a 100\% de adequação); Grupo 2 Bom (70 a 90\% de adequação); Grupo 3 - Regular (50 a 69\% de adequação); Grupo 4 - Ruim (20 a $49 \%$ de adequação), e Grupo 5 - Muito ruim (0 a $19 \%$ de adequação). 
Após a classificação da unidade foram elaborados planos de ação para as não conformidades encontradas que necessitavam maior atenção, verificadas durante a aplicação da lista de verificação em boas práticas. Salienta-se que a execução do plano de ação ocorreu em um período de nove meses.

Foram realizadas cinco capacitações com as manipuladoras de alimentos, em forma de conversa e dinâmicas de grupo (15 a 20 minutos). As capacitações abordaram os seguintes temas: DTAs, contaminação de alimentos, manipulação higiênica dos alimentos e higiene pessoal.

Além das capacitações foram elaboradas planilhas de registros (higienização de ambientes e equipamentos, calibração de equipamentos, manutenção preventiva dos equipamentos, temperatura de cocção dos alimentos, temperatura de distribuição dos alimentos, realização de exames de saúde dos manipuladores de alimentos, temperatura dos equipamentos de frio, temperatura do recebimento de matérias-primas, controle integrado de pragas e higienização do reservatório de água), instruções de trabalho (coleta de amostras, higienização correta das mãos, higienização das hortifrutícolas e organização dos equipamentos de frio), e padronização das coletas de amostras de alimentos.

A unidade de alimentação e nutrição da ILPI foi novamente avaliada mediante a reaplicação da lista de verificação, aproximadamente três meses após a implantação das ações supracitadas.

Os dados coletados foram digitados e tabulados com o auxílio do programa Microsoft Office Excel ${ }^{\circledR}$, versão 2013 e a figura formulada por meio do programa GraphPad Prism versão 5.0. Os dados foram submetidos à análise estatística descritiva simples (média e percentual de conformidade), com auxílio do programa Statistica versão 7.0.

\section{RESULTADOS E DISCUSSÃO}

Após a aplicação inicial da lista de verificação em Boas Práticas de Manipulação de Alimentos a unidade de alimentação e nutrição avaliada apresentou 41,27\% de adequação, sendo classificada no Grupo 4
-Ruim (20 a 49\% de adequação). De acordo com Stedefeldt ${ }^{[1]}$ para um serviço de alimentação estar adequado do ponto de vista higiênico-sanitário, o ideal seria apresentar acima de 75\% de adequação. Destacase que uma pontuação abaixo deste percentual é considerada como "não adequada" quando se refere às Boas Práticas, portanto, a unidade de alimentação avaliada obteve um resultado abaixo do recomendado. Salienta-se que a identificação dos itens não conformes pode auxiliar o diagnóstico da adequação das Boas Práticas em unidades de alimentação e nutrição, uma vez que esses itens podem colaborar na prevenção da incidência de surtos decorrentes de contaminações alimentares ${ }^{[12]}$.

Estudos realizados por Silveira ${ }^{[13]}$ e Lopes $e t$ al. [14] avaliaram as condições higiênico-sanitárias em unidades de alimentação e nutrição de ILPIs. O primeiro estudo, constatou um percentual de $65,90 \%$ de adequação na unidade avaliada, onde todos os itens apresentaram não conformidades, exceto "documentação e registro". Já o segundo, observou que das 14 ILPIs que foram analisadas, apenas uma atingiu adequação em mais de $75 \%$ dos itens na lista de verificação, e a grande maioria das instituições atendeu menos de $50 \%$ de adequação.

Já o estudo de Akutsu[15], realizado em restaurantes comerciais em Brasilia, corrobora com os resultados encontrados, onde $80 \% \quad(n=8)$ dos estabelecimentos avaliados foram classificados entre $30 \%$ e $70 \%$ de adequação. Destaca-se que os estudos citados foram realizados com uma lista de verificação elaborada pelos autores baseada na RDC no $216 / 2004[4]$ o que pode ter contribuído para a diferenciação nos itens avaliados.

Foram realizadas ações visando a implantação das Boas Práticas durante nove meses na ILPI avaliada. Dentre estas, destaca-se a elaboração de capacitações, planilhas de registro, instruções de trabalho e implantação da coleta de amostras e aferição da temperatura de cocção e distribuição dos alimentos ofertados aos idosos.

Posteriormente à implantação destas ferramentas de controle e capacitações foi novamente aplicada a LVBP, sendo que o percentual médio de adequação encontrado foi de 56\%. Este acréscimo de $14,73 \%$ de adequação entre as duas aplicações foi estatisticamente significativo $(p<0,001)$, uma vez que a 
classificação da unidade subiu em uma categoria, sendo classificada no Grupo 3 (Regular).
No Gráfico 1, pode-se verificar o percentual de adequação das boas práticas por categoria avaliada em ambas as aplicações da lista de verificação.

Gráfico 1.Distribuição do percentual de adequação após a aplicação inicial e final da Lista de Verificação em Boas Práticas (LVBP) em uma ILPI
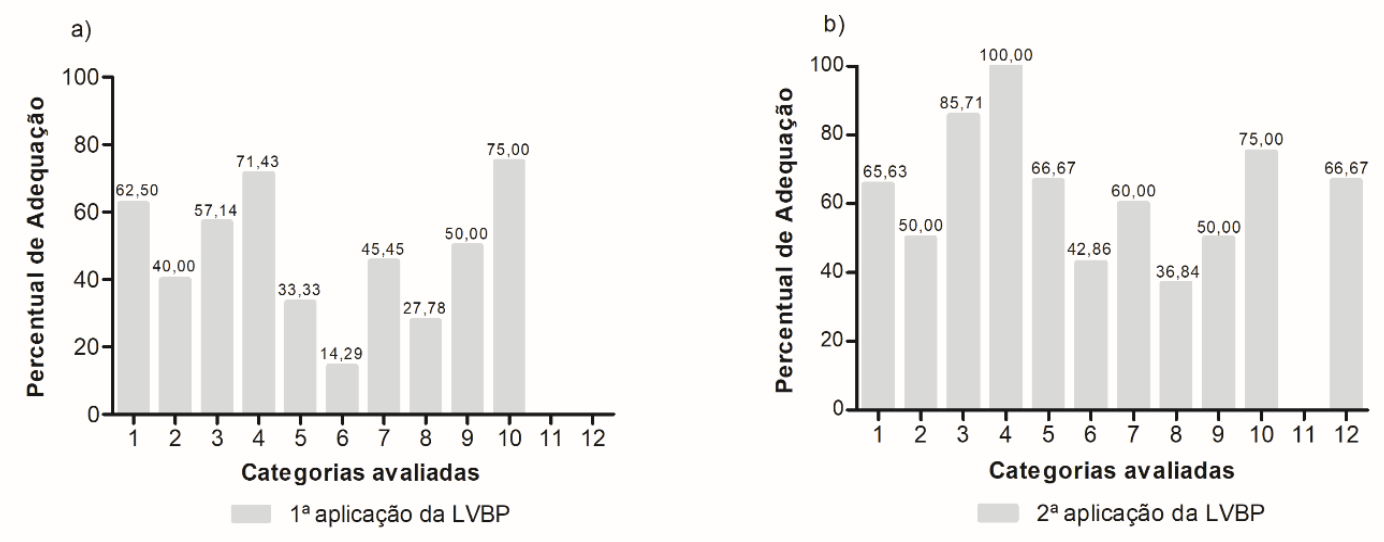

Fonte: Dados obtidos pelos autores

Após a primeira aplicação da LVBP, ao elaborar uma avaliação das 12 categorias, pode-se observar que cinco delas (Edificação, Instalações, Equipamentos, Móveis e Utensílios; Controle Integrado de Pragas; Abastecimento de Água; Armazenamento e Transporte do Alimento preparado e Exposição ao Consumo do Alimento Preparado) apresentaram um percentual pelo menos igual a 50\% de adequação, sendo que as categorias Abastecimento de Água e Exposição ao Consumo do Alimento Preparado encontraram-se acima de 70\%. Destas categorias, duas foram classificadas no Grupo 2 (Bom) e o restante no Grupo 3 (Regular). Já as categorias Documentação e Registro e Responsabilidade não apresentaram percentual de adequação, sendo classificadas no Grupo 5 (Muito Ruim).

$\mathrm{Na}$ categoria relacionada a Edificação, Instalações, Equipamentos, Móveis e Utensílios houve um aumento no percentual de adequação de 3,13\% entre a aplicação inicial e final da LVBP. Este aumento deve-se à instalação de telas milimetradas nas janelas da área de preparação de alimentos, elaboração de planilhas de registro para calibração de instrumentos de medição e manutenção preventiva de equipamentos. Algumas alterações estruturais (instalação de portas automáticas na área de preparo de alimentos, troca do teto de madeira por outro de material de fácil higienização, reforma para embutir fiações elétricas, entre outras) encontram-se em um plano de ação, porém, nem todos os orçamentos são factíveis com a realidade da unidade; este plano contemplou ações para corrigir cada não adequação encontrada. Esta categoria é considerada como uma fonte de contaminação secundária, do ponto de vista sanitário, uma vez que se referem a reservatórios de microrganismos de origem não alimentar [16].

Um estudo realizado por Ferreira et al.[17] envolvendo nove unidades de alimentação e nutrição de restaurantes comerciais em Minas Gerais, constatou que o percentual de adequação nesse bloco variou de $71,40 \%$ a $90,50 \%$. De todas as não conformidades encontradas, as objeções mais frequentes foram relacionadas aos equipamentos de conservação dos alimentos que não estavam em adequado estado de funcionamento, assim como a falta de registros de manutenção preventiva dos equipamentos. As 
inadequações supracitadas divergiram do presente trabalho, uma vez que o teto da unidade avaliada é de difícil higienização por ser de madeira, portas da área de preparação não possuem fechamento automático, lâmpadas não são dotadas de proteção contra explosões, algumas fiações não se encontram embutidas e o sabonete líquido utilizado nas instalações sanitárias e lavatório não é inodoro. A não adequação que corrobora entre os dois estudos é a inexistência de registros de manutenção preventiva dos equipamentos.

A categoria referente a Higienização de Instalações, Equipamentos, Móveis e Utensílios apresentou um aumento de $10 \%$ após a reaplicação da LVBP, devido a modificação do processo de higienização de ambientes. Ainda, foram realizadas modificações na diluição, tempo de contato e modo de aplicação dos produtos químicos e substituição de produtos saneantes não registrados no Ministério da Saúde por outros próprios para uso em alimentos. Também houve a elaboração de planilha com escala dos manipuladores de alimentos para a realização da higienização da área de preparo e distribuição dos alimentos.

A higienização dentro de um serviço de alimentação é essencial, uma vez que as superfícies das instalações, dos equipamentos, móveis e utensílios estão em contato direto e indireto com os alimentos constituindo um elemento de contaminação quando não realizado da forma adequada[18].

Pode-se observar na UAN avaliada, a inexistência de registro das operações de limpeza, higienização dos panos não descartáveis realizada de forma incorreta, uma vez que inexiste o uso de solução clorada e detergente neutro na realização deste processo e os produtos saneantes utilizados não são registrados pelo Ministério da Saúde. As duas primeiras não conformidades supracitadas também foram observadas por Cardozo et al.[19], que avaliaram a segurança de alimentos em UANs de escolas de Salvador. Ainda neste estudo, foi constatado que os critérios de diluição e tempo de contato nos procedimentos não eram seguidos e caixas de gordura não passavam por limpeza periódica, o que facilitava $\mathrm{o}$ retorno dos resíduos para a área de preparação e favorecia a disseminação de contaminantes.
A categoria alusiva ao Controle Integrado de Pragas mostrou um aumento significativo de $28,57 \%$ entre as aplicações da LVBP. Este crescimento no percentual de adequação, na segunda aplicação, devese ao fato que as áreas de produção do serviço de alimentação se encontraram livres da presença de insetos, como na primeira. Houve, ainda, a instalação de telas milimetradas nas janelas e portas da área de produção de alimentos da ILPI, controle de pragas realizado por empresa especializada com entrega de laudo e elaboração de planilha de controle para registro da realização das dedetizações.

O controle de pragas apresenta ações preventivas e corretivas de extrema importância para a qualidade higiênico-sanitária dos alimentos produzidos por um serviço de alimentação, pois impede o ingresso e a multiplicação de vetores e pragas urbanas. Dentre estas ações destaca-se a presença de telas milimetradas nas janelas, higienização das instalações, equipamentos, móveis e utensilios, um manejo adequado dos resíduos, eliminação de frestas e fendas, fixação de molas e reforço na soleira de portas ${ }^{[5,16]}$.

Esta categoria apresentou como única "não adequação" o fato da inexistência de um registro que comprove a regularização dos produtos químicos utilizado, uma vez que acontece apenas a descrição dos mesmos pela empresa terceirizada responsável pelas desinsetização. Este resultado difere do estudo de Mello et al. [12] onde este grupo apresentou 100\% de adequação em todas os sete restaurantes comerciais avaliados. Este estudo, ainda, afirma que a realização do controle de pragas e vetores é fundamental em serviços de alimentação, pois a presença destes fornece risco de transmissão de doenças e foco de dissipação de sujidades.

A categoria relativa ao Abastecimento de Água apontou um aumento significativo de 28,57\% quando comparada à primeira aplicação da LVBP, atingindo o percentual de 100\%. Este percentual ocorreu porque o reservatório de água da ILPI foi higienizado por empresa especializada após a primeira aplicação da lista de verificação e também, à elaboração de planilha de controle para registro de higienização da caixa d'água da instituição.

Em Unidades de Alimentação e Nutrição, que a água é utilizada em processos de higienização, produção de alimentos e para ingestão direta, é 
fundamental a adoção de práticas para o controle rotineiro de higienização dos reservatórios para que assim, a segurança dos alimentos não seja colocada em risco[ ${ }^{200]}$.

Silva et al.[21] averiguaram,após realização de estudo em cinco UANs do município de Duque de Caxias (Rio de Janeiro - RJ), que uma das unidades não estava de acordo com a legislação em vigor no que diz respeito à manutenção e higienização dos reservatórios de água, uma vez que as mesmas não eram mantidas fechadas adequadamente e inexistia um programa de limpeza dos reservatórios de água. Já o presente estudo não apresentou nenhuma não conformidade, o que significa que a categoria em questão não fornece nenhum risco de contaminação para a unidade.

A categoria referente ao Manejo de Resíduos obteve aumento de 33,34\% no percentual de adequação após a 2a aplicação da lista de verificação, uma vez que foram realizadas capacitações com as manipuladoras de alimentos e os coletores de resíduos da área de produção que não continham identificação passaram a ser identificados.

As capacitações ministradas contemplaram como tema a separação adequada de resíduos orgânicos e não orgânicos da área de produção de alimentos, assunto este que causava certa preocupação na unidade. Em serviços de alimentação existe a necessidade do manejo dos resíduos (coleta e estoque), que deve acontecer em local fechado e afastado da produção e estoque de matérias-primas, para que se evite a contaminação dos alimentos e a atração de pragas urbanas ${ }^{[5]}$.

A unidade avaliada apresentou a estocagem dos resíduos coletados, como não adequação, esta é realizada em local aberto e sem nenhum tipo de isolamento. De acordo com Souza et al.[22] uma UAN hoteleira, apresentou-se com 100\% de não conformidade, onde resíduos puderam ser observados expostos em local aberto e próximo a área de armazenamento; a área de preparação apresentou lixeiras sem acionamento manual pelos manipuladores, porém estas lixeiras não eram utilizadas.

A categoria Manipuladores obteve um aumento significativo de $28,57 \%$ após a reaplicação da lista de verificação na ILPI. Este acréscimo se dá devido às várias ações que foram realizadas ao longo dos nove meses da implantação das boas práticas e que anteriormente não existiam, tais como: afixação de instrução de trabalho sobre a higienização correta das mãos; capacitação dos manipuladores relacionadas a higiene pessoal, manipulação de alimentos, doenças transmitidas por alimentos e Boas Práticas e elaboração de planilhas de controle relacionadas ao registro das capacitações. É imprescindível que os manipuladores de alimentos sejam capacitados com frequência mínima de uma vez ao ano[].

Nesta categoria, os fatores de risco de contaminação e doenças transmitidas por alimentos mais comuns foram referentes à displicência das Boas Práticas, principalmente quando se menciona as práticas de higienização dos manipuladores. Então surge a importância de implementar ações que abranjam um conjunto de medidas essenciais para a produção de alimentos seguros. As capacitações oferecem aos funcionários referências que servirão para o engrandecimento de suas habilidades, com o intuito de torná-los ainda mais aptos ao trabalho[23]. O manipulador é o componente de maior importância dentro do serviço de alimentação, uma vez que são incumbidos por implementar as Boas Práticas [24].

Um estudo realizado por Santos; Rangel e Azeredo ${ }^{[25]}$ envolvendo cinco UANS de restaurantes comerciais do Rio de Janeiro mostrou que em relação aos manipuladores, $100 \%$ dos estabelecimentos não apresentaram registro de controle de saúde dos manipuladores que, por sua vez, não possuíam nenhuma capacitação em higiene registrada, conforme preconizado pela legislação[ ${ }^{[5]}$, resultando na inaptidão para atuarem como manipuladores. Neste estudo na ILPI, foi observado o uso inadequado do uniforme pelos manipuladores e uso de adornos, higienização incorreta das mãos, inexistência de capacitação na admissão e ausência de registros e planilhas de controle de saúde. Manipuladores utilizando adornos e uniformes incompletos foram inadequações também encontradas em estudo realizado por Almeida e Saccol[26].

A categoria Matérias-primas, Ingredientes e Embalagens apresentou um aumento de 14,55\% quando comparado à primeira aplicação da LVBP. Tal situação refere-se ao correto armazenamento de diferentes gêneros alimentícios nos equipamentos de frio após a capacitação realizada, elaboração de 
instrução de trabalho para que este armazenamento fosse realizado de forma correta, elaboração de etiquetas para embalagens fracionadas e elaboração de planilha para registro de temperaturas no recebimento das matérias-primas da ILPI.

Em um serviço de alimentação a recepção da matéria-prima é vista como um ponto de monitoramento. A cautela com a escolha de fornecedores e a verificação dos produtos no recebimento formam exigências que colaboram para a preservação da qualidade e inocuidade do produto[ ${ }^{[5]}$.

Observou-se que nem todas as embalagens dos alimentos são inspecionadas no recebimento na ILPI. Ainda, a instituição avaliada, não possui registro do controle da temperatura no recebimento e no armazenamento e as prateleiras para estocagem dos alimentos encontram-se próximas ao chão. Miranda\& Baião ${ }^{[27]}$ diagnosticaram não conformidades relacionadas principalmente às falhas nos critérios estabelecidos para a seleção dos fornecedores, fato este não encontrado no presente estudo.

Quando se trata da categoria Preparação do Alimento, pode-se verificar um aumento de $9,06 \%$ na adequação da unidade. Este aumento ocorreu pelo início do monitoramento e registro da temperatura dos alimentos durante a cocção e distribuição aos idosos. Também passou a ser realizado o armazenamento de 100 gramas de amostras de todos os alimentos preparados, incluindo bebidas. Ainda nesse quesito, foi elaborada uma planilha de padronização das coletas de amostras de alimentos, contendo os alimentos usualmente preparados na ILPI e suas respectivas medidas caseiras, a modo de facilitar esta coleta. Durante a primeira aplicação da lista foi possível verificar a inexistência da coleta de amostras e o monitoramento de temperatura dos alimentos. Esta coleta é importante para auxiliar no esclarecimento de possíveis ocorrências de doenças transmitidas por alimentos e água ${ }^{[28]}$.

O estudo realizado por Almeida \& Saccol[26] em serviços de alimentação de cinco terminais rodoviários revela que todos os estabelecimentos visitados possuem um percentual de adequação insatisfatório em relação à categoria em questão, devido a presença de embalagens das matérias-primas violadas, produtos perecíveis expostos à temperatura ambiente por tempo maior do que o recomendado (30 min.), descuido do controle térmico dos alimentos e falta de monitoramento das temperaturas e qualidade de óleos e gorduras. Já no presente estudo as não conformidades se resumem a fatores como manipulação de alimentos junto à pia de higienização, equipamentos de refrigeração não atingiram a temperatura referida na legislação, não há existência de registros de temperatura de refrigeração e congelamento e o tempo de exposição de alimentos perecíveis em temperatura ambiente é maior do que uma hora.

Nas categorias Armazenamento e Transporte do Alimento preparado, Exposição ao Consumo do Alimento preparado e Documentação e Registro não apresentaram modificação no percentual de adequação relacionado as Boas Práticas. A unidade não possui os Procedimentos Operacionais Padronizados (POPs), todavia, destaca-se que estes documentos se apresentam em processo de elaboração, mas ainda não foram implantados. É obrigatória a apresentação de documentação como essa em serviços de alimentação, porém, isso não pode ser usado como parâmetro para afirmar que os manipuladores realizam tal procedimento, ou ainda, não dá a certeza de que quando realizado seja da forma correta ${ }^{[29]}$.

Em relação ao armazenamento de alimentos, os mesmos devem ser estocados apenas em áreas adequadas, ou seja, o ideal é que não entrem em contato direto com o piso. Deve ser realizado sobre prateleiras que mantenham distância necessária do forro, paredes e piso, a fim de garantir ventilação, limpeza, desinfecção do local ou circulação de pessoas, apropriados ${ }^{[4,6,30]}$. A não adequação se resume aos alimentos perecíveis armazenados em temperatura ambiente, sem tampa, por um período superior a 30 minutos. Já o estudo de Silva et al.[9], realizado em duas UANs localizadas no município de Vitória - ES, encontrou como não adequação das unidades a inexistência de controle do tempo e da temperatura dos alimentos durante o tempo de espera para a distribuição.

A categoria Responsabilidade obteve o maior aumento de percentual, atingindo $66,67 \%$ de adequação. Isto aconteceu porque os responsáveis pelas atividades de manipulação dos alimentos foram submetidos durante a implantação das Boas Práticas a cursos de capacitação supracitados. Após estes cursos 
os manipuladores de alimentos receberam um documento comprovando as atualizações.

Cabe ao manipulador de alimentos portar comprovação de capacitação em cursos de noções básicas em contaminantes alimentares, doenças transmitidas por alimentos, manipulação higiênica dos alimentos e Boas Práticas ${ }^{[3]}$.

Danelon \& Silva ${ }^{[30]}$ destacam a essencialidade da implantação de capacitações destinadas aos manipuladores, a fim de que estes produzam refeições de qualidade e inócuas, protegendo assim a saúde dos comensais e do próprio manipulador.

A questão da promoção de capacitações, no mínimo anuais, ainda está sendo implantada na UAN da ILPI por responsável pelas atividades de manipulação, o que ainda não permite o percentual de $100 \%$ de adequação nesta categoria, como o encontrado por Carvalho et al. ${ }^{31]}$.

Diante dos resultados, a preocupação com a saúde dos idosos se faz presente, uma vez que possuem necessidades nutricionais específicas em comparação com as demais faixas etárias. Uma alimentação segura e saudável é um fator essencial para a saúde e qualidade de vida das pessoas, pois influencia o equilíbrio emocional e o bem-estar na prevenção de danos à saúde e tratamento dos idosos. Consequentemente, deve ser adequada nutricionalmente e segura, sem oferecer riscos à saúde[32,33],

\section{CONCLUSÃO}

Embora a UAN da ILPI avaliada tenha sido classificada primeiramente no Grupo Ruim, após a implantação de ações relacionadas às Boas Práticas houve uma melhora nessa classificação, com aumento para o Grupo Regular. Os aumentos mais significativos no percentual de adequação, foram nas categorias Controle Integrado de Pragas, Abastecimento de Água, Manejo de Resíduos, Manipuladores e Responsabilidade.

Ainda existem itens a serem melhorados, alguns inclusive se encontram em projeto de desenvolvimento para futura implantação. $\mathrm{O}$ maior empecilho para a plena realização deste projeto se deu ao fato de que um número significativo de não adequações estava relacionado à parte estrutural da unidade, e para adequá-las é necessário um valor orçamentário não factível com a realidade da unidade.

Ressalta-se assim, a importância das Boas Práticas em serviços de alimentação e a implantação das mesmas, a fim de proporcionar qualidade e inocuidade dos alimentos conforme a legislação sanitária, garantindo a segurança alimentar aos idosos institucionalizados.

\section{REFERÊNCIAS}

[1] Santos C, Santos E, Branco V, Soares C, Saraiva A. Segurança Alimentar em grupos de risco. Rev. Psicol. 2014;6(1):337-342.

[2] Brasil. Agência Nacional de Vigilância Sanitária. Consulta Pública no-41. Diário Oficial da União. Brasília;18 jun 2004.

[3] Lopes JA. Instituições de Longa Permanência: avaliando a dieta de idosos e as condições estruturais e higiênicosanitárias das Unidades de Alimentação e Nutrição [dissertação]. Salvador: Universidade Federal da Bahia; 2014.

[4] Brasil. Agência Nacional de Vigilância Sanitária. Cartilha sobre Boas Práticas para Serviços de Alimentação: Resolução - RDC no 216/2004 [Internet]. 2004 [acesso em 08 out 2019]. Disponível em: http:/ / www.anvisa.gov.br

[5] Brasil. Resolução RDC no 216, de 15 de setembro de 2004. Dispõe sobre regulamento técnico de boas práticas para serviços de alimentação. Diário Oficial da União. Brasília; 15 set 2004.

[6] Rio Grande do Sul. Secretaria da Saúde. Portaria no78, de 30 de janeiro de 2009. Aprova a Lista de Verificação em Boas Práticas para Serviços de Alimentação, aprova Normas para Cursos de Capacitação em Boas Práticas para Serviços de Alimentação e dá outras providências. Diário Oficial. Porto Alegre; 30 jan 2009.

[7] Brasil. Ministério da Saúde. Surtos de Doenças Transmitidas por Alimentos no Brasil, 2019 [Internet]. 2019 [acesso em 15 nov 2019]. Disponível em: https://portalarquivos2.saude.gov.br/images/pdf/2019/ma io/17/Apresentacao-Surtos-DTA-Maio-2019.pdf.

[8] Silva SMR. Importância da Utilização das Ferramentas de Gestão da Qualidade para a Produção de Alimentos Seguros - Análise de uma Unidade de Alimentação e Nutrição 
(UAN) na Cidade de Belém - PA [dissertação]. Lisboa: Repositório Científico Lusófona; 2012.

[9] Silva LC, Santos DB, São José JFB, Silva EMM. Boas práticas na manipulação de alimentos em Unidades de Alimentação e Nutrição. Demetra. 2015;10(4):797-820.

[10] Saccol ALF, Hecktheuer LH, Richards NS, Stangarlin L. Lista de avaliação de Boas Práticas para Serviços de Alimentação - Resolução - RDC 216/2004 - ANVISA. São Paulo: Varela; 2006.

[11] Stedefeldt E, Cunha DT, Silva JREA, Silva S M, Oliveira ABA. Instrumento de avaliação das Boas Práticas em Unidades de Alimentação e Nutrição Escolar: da concepção à validação. Ciênc. Saúde Coletiva. 2013;18(4):947-953.

[12] Mello JF, Schneider S, Lima MS, Frazzon J, Costa M. Avaliação das condições de higiene e da adequação às Boas Práticas em Unidades de Alimentação e Nutrição no Município de Porto Alegre - RS. Alimentação \&Nutrição. 2013;24(2):175-182.

[13] Silveira SM. Avaliação das Condições Higiênicas Sanitárias da UAN de um Asilo em Planaltina [dissertação]. Brasilia: Centro Universitário de Brasillia; 2011.

[14] Lopes JA et al. Avaliação das Unidades de Alimentação e Nutrição em Instituições de Longa Permanência para Idosos. Alimentação em Instituições Geriátricas. Revista Geriatria e Gerontologia. 2012:98-103.

[15] Akutsu RT, Botelho RA, Camargo EB, Sávio KEO, Araújo WC. Adequação das boas práticas de fabricação em serviços de alimentação. Rev. Nutr. 2005;18(3):419-427.

[16] Silva Júnior EA. Manual de Controle Higiênico Sanitário em Alimentos. 7. ed. São Paulo: Varela; 2014.

[17] Ferreira MA, São José JFB, Tomazini APB, Martini HSD, Milagres RCM, Pinheiro-Santana HM. Avaliação da adequação às Boas Práticas em Unidades de Alimentação e Nutrição. Rev.Inst. Adolfo Lutz [Internet]. 2011 [acesso em 03 jun 2019]. 2011;70(2):230-235. Disponível em: http://periodicos.ses.sp.bvs.br/pdf/rial/v70n2/v70n2a20.p df.

[18] Baptista P. Higienização de Equipamentos e Instalações na Indústria Agroalimentar. Consultoria em Formação Integrada. Guimarães: Forvisão; 2003.

[19] Cardoso RCV et al. Programa nacional de alimentação escolar: há segurança na produção de alimentos em escolas de Salvador (Bahia)? Rev. Nutr. [Internet]. 2010 [acesso em 03 jul 2019]; 23(5):801-811. Disponível em: http://www.scielo.br

[20] Cardoso RCV, Souza EVA, Santos PQ. Unidades de Alimentação e Nutrição nos Campis da Universidade Federal da Bahia: um estudo sob a perspectiva de alimento seguro. Rev. Nutr. [Internet]. 2005 [acesso em 15 jul 2019];18(5):669-680. Disponível em: http://www.scielo.br

[21] Silva DO, Oliveira EA, Braga GA, Costa GF, Feijó TS, Cardozo SV. Reconhecimento dos riscos ambientais presentes em Unidades de Alimentação e Nutrição no Município de Duque de Caxias, RJ. Rev. Saúde \& Ambiente. 2008;3(2):1-6.

[22] Souza CH, Sathler J, Jorge MN, Horst RFML. Avaliação das condições higiênico sanitárias em uma Unidade de Alimentação e Nutrição hoteleira, na cidade de Timóteo -MG. Rev. Dig. Nutrição. 2009;3(4):312-329.

[23] Araújo LM, Bragança EB, Amaral TGA, Castro FT, Tabai KC. Segurança do alimento: condições higiênicosanitárias do restaurante de empresa do município do Rio de Janeiro - RJ [Internet]. Rio de Janeiro; 2009 [acesso em 17 jul 2019]. Disponível em: http://www.xxcbed.ufc.br

[24] Andreotti A, Baleroni FH, Paroschi VHB, Panza SGA. Importância do treinamento para manipuladores de alimentos em relação à higiene pessoal. Rev. Inic. Cientifica - Cesumar. 2003;5(1):29-33.

[25] Santos MOB, Rangel VP, Azeredo DP. Adequação de restaurantes comerciais às Boas Práticas. Rev. Hig. Alimentar. 2010;24:190-191.

[26] Almeida LA, Saccol ALF. Avaliação das Boas Práticas em Serviços de Alimentação de Terminais Rodoviários no Estado do Rio Grande do Sul. Brazilian Journal of Food Technology. 2010;nov:16-22.

[27] Miranda ACB, Baião RCL. Avaliação das Boas Práticas na fabricação de preparações à base de pescados crus em restaurante japonês. Revista Eletrônica da Fainor. 2011;4(1):52-61.

[28] São Paulo. Secretaria de Estado da Saúde. Portaria CVS 5 , de 09 de abril de 2013. Aprova o regulamento técnico sobre boas práticas para estabelecimentos comerciais de alimentos e para serviços de alimentação, e o roteiro de inspeção, anexo [Internet]. Diário Oficial. 2013[acesso em 31 mai 2019]. Disponível em: http://www.cvs.saude.sp.gov.br 
[29] Brasil, Serviço Nacional de Aprendizagem Comercial SENAC. Manual de elementos de apoio para o Sistema APPCC. SENAC/Departamento Nacional. Rio de Janeiro; SENAC; 2001.

[30] Danelon MS, Silva MV. Análise das condições higiênico-sanitárias das áreas de preparo e consumo de alimentos disponíveis para alunos de escolas públicas e privadas. Rev. Hig. Alimentar. 2007;21(52):25-30.

[31] Carvalho LSC, Ribeiro MRS, Sousa CL, Nascimento VHA. Boas práticas e qualidade sanitária dos alimentos servidos em restaurantes do tipo self-service no campus da Universidade Federal do Pará. Segur. Aliment. Nutr. 2016;(23):924-932.

[32] Davim RMB, Torres GV, Dantas SMM, Lima VM. Estudo com idosos de instituições asilares no Município de Natal -RN: características socioeconômicas e de saúde. Revista Latino-Americana de Enfermagem. 2004;12(3):518524.

[33] Brasil. Sistema Único de Saúde (SUS). Orientações da Vigilância Sanitária para Instituições de Longa Permanência para Idosos. Belo Horizonte: SUS; 2016. 